ISSN: 2594-4827

\title{
O PROCESSO DE ABERTURA DE NOVOS CURSOS: UM PANORAMA DOS DOCUMENTOS QUE ORIENTAM AS AÇÕES DOS INSTITUTOS FEDERAIS DA REGIÃO SUL DO PAÍS
}

Patricia Custódio dos Santos Neves ${ }^{1}$

Leandro Rafael Pinto ${ }^{2}$

Recebido em: julho/2019

Publicado em: dezembro/2019

\section{Resumo:}

Este artigo trata do movimento de expansão e oferta de educação profissional pelas Instituições que compõem a Rede Federal de Educação Profissional, Científica e Tecnológica, cuja ampliação passa necessariamente pela a abertura de novos cursos. Destacando os Institutos Federais, tem-se que entre suas finalidades está ministrar educação profissional técnica de nível médio, prioritariamente na forma de cursos integrados. Buscou-se nesta pesquisa investigar e demonstrar os documentos que orientam o processo de indicação de novos cursos que impulsionam a expansão da Educação profissional ofertada pelos Institutos Federais. Para o desenvolvimento deste trabalho a metodologia utilizada foi qualitativa, tendo como objetivo apresentar um panorama dos documentos produzidos para nortear o processo de criação e abertura de novos cursos, buscando elencar, em especial o que foi produzido para os cursos técnicos integrados. Realizou-se para isto uma pesquisa documental, para análise das leis e documentos que regem e orientam as propostas de abertura de novos cursos; um estudo de caso para mapear os documentos disponibilizados em meio eletrônico pelos IF (Institutos Federais de Educação) da região sul do país e uma análise de conteúdos para investigar e elencar as ações indicadas para se estruturar uma metodologia de escolha de novos cursos, feitas pelos campi do IFPR no PDI (Plano de Desenvolvimento Institucional) 2014/2018. Diante do panorama apresentado neste estudo, pode-se afirmar que não são muitos os documentos que orientam e disciplinam a criação e abertura de novos cursos, em particular os técnicos integrados. E as Instituições Federais de Educação seguem com o grande desafio de atender a legislação educacional pertinente buscando $\mathrm{o}$ atendimento às demandas socioeconômico-ambientais dos cidadãos e do mundo do trabalho quando fazem a escolha e a indicação de um eixo e/ou cursos a serem oferecidos. Aponta-se ainda a necessidade de novas pesquisas e estudos que tratem desta temática, e que possam colaborar para que este processo aconteça em parceria com a sociedade e em beneficio da transformação social e do desenvolvimento local e regional.

Palavras chaves: Educação Profissional. Institutos Federais. Cursos Técnicos Integrados. Abertura de novos cursos.

\footnotetext{
${ }^{1}$ Instituto Federal do Paraná. E-mail: pcustodiosantosn@gmail.com

${ }^{2}$ Instituto Federal do Paraná. E-mail: leandro.rafael@ifpr.edu.br
} 


\title{
THE OPENING PROCESS OF NEW COURSES: A PARANORAMA OF THE DOCUMENTS THAT GUIDE THE ACTIONS OF THE FEDERAL INSTITUTES IN THE SOUTHERN REGION OF THE NATION
}

\begin{abstract}
:
This article deals with the movement of expansion and offer of professional education by the Institutions that compose the Federal Network of Professional, Scientific and Technological Education, whose expansion necessarily involves the opening of new courses. Highlighting the Federal Institutes, one has that among its purposes is to provide technical education of secondary level, mainly in the form of integrated courses. This research sought to investigate and demonstrate the documents that guide the process of nominating new courses that drive the expansion of professional education offered by the Federal Institutes. For the development of this work the methodology used was qualitative, aiming to present an overview of the documents produced to guide the process of creation and opening of new courses, seeking to list, especially what was produced for the integrated technical courses. For this, a documentary research was carried out to analyze the laws and documents that govern and guide the proposals to open new courses; a case study to map the documents made available electronically by the IF (Federal Institutes of Education) of the southern region of the country and a content analysis to investigate and list the actions indicated to structure a methodology for choosing new courses, made by the IFPR campuses in the PDI (Institutional Development Plan) 2014/2018. Given the scenario presented in this study, it can be said that there are not many documents that guide and discipline the creation and opening of new courses, in particular the integrated technicians. And the Federal Institutions of Education continue with the great challenge of meeting the relevant educational legislation seeking to meet the socioeconomic and environmental demands of citizens and the world of work when making the choice and indication of an axis and / or courses to be offered. It also points out the need for further research and studies that address this issue, and that can collaborate to make this process happen in partnership with society and for the benefit of social transformation and local and regional development.
\end{abstract}

Keywords: PROFESSIONAL EDUCATION; FEDERAL INSTITUTES; INTEGRATED TECHNICAL COURSES; OPENING OF NEW COURSES.

\section{INTRODUÇÃO}

Segundo o Ministério da Educação (2019), uma das características da formação da Rede Federal de Educação Profissional, Científica e Tecnológica (Rede Federal) foi a implantação de 
uma nova concepção sobre o papel e a presença do sistema de ensino federal na oferta pública da educação profissional e tecnológica.

Os Institutos Federais são instituições que compõem, em sua maioria, esse sistema educacional, e deve-se considerar que o Estado entende os Institutos Federais na perspectiva de contribuição para o processo de modernização e desenvolvimento do país, oferecendo uma educação profissional e tecnológica os cidadãos que leve em conta os arranjos produtivos e os aspectos sociais, culturais locais (TURMEN, AZEVEDO, 2017, p. 1073).

Este estudo trata de um ponto além dos apontamentos feitos pelos autores. Aborda-se outra característica dos Institutos Federais de Educação, que é a obrigatoriedade legal de garantir que no mínimo $50 \%$ de suas vagas sejam destinadas a oferta de cursos técnicos de nível médio prioritariamente na forma integrada, como afirma a lei $\mathrm{n}^{\circ} 11.892 / 08$.

Tendo em vista o importante espaço que os cursos técnicos integrados ocupam na oferta de educação profissional oferecida pelos Institutos Federais, este estudo se dedica a investigar os documentos que orientam a escolha e indicação de novos cursos técnicos integrados oferecidos por estas instituições. Esta escolha se deve pelo que afirma o Decreto $n^{\circ} 9.235 / 2017$, relatando que as instituições da Rede Federal de Educação só poderão oferecer cursos superiores nas áreas em que ofertam cursos de nível médio.

Este ponto torna mais relevante a seleção e indicação de eixos e/ou cursos técnicos integrados que beneficiem a sociedade como um todo, e não atenda apenas os anseios do mercado de trabalho, pois a verticalização dos cursos deve acontecer subsidiados nas escolhas feitas para esta modalidade. Uma das hipóteses que se tem neste estudo é a inexistência de uma metodologia que oriente a seleção e indicações de novos cursos técnicos integrados.

Ressalta-se que as Instituições Federais de Educação, embora tenham alguns documentos legais que disciplinem sobre as propostas de aberturas de novos cursos, não consigam desenvolver plenamente este processo em integração com a sociedade, e muitas vezes são conduzidas a atender os anseios do mercado do trabalho, ao levantar e considerar apenas dados econômicos de uma região, desconsiderando os aspectos culturais, sociais e educacionais de uma localidade, quando fazem os estudos para indicação de um novo curso.

Em pesquisa aos documentos que disciplinam o processo de criação de novos cursos, encontram-se como escopo leal e pedagógico a Resolução CNE/CEB nº 6, de 20 de setembro de 2012, que define as Diretrizes Curriculares Nacionais para a Educação Profissional Técnica de Nível Médio, a lei de criação da Rede Federal n 11.982/08, o Decreto Federal n ${ }^{\circ}$ 9.235/2017 e o Catálogo Nacional de Cursos Técnicos que deve sua terceira edição atualizada em 2014. 
Foi feita uma pesquisa aos portais dos Institutos Federais buscando documentos publicados em meio eletrônico que dessem orientações específicas para o processo de abertura de novos cursos, além dos Planos de Desenvolvimentos Institucionais (PDI). Na busca foram encontrados poucos documentos, pois os instrumentos que tratam da temática pesquisada têm nomes diversos, o que torna mais difícil a pesquisa e coleta de dados.

Foram encontrados poucos documentos institucionais, entre eles: um que dispõe sobre a alteração da Instrução Normativa para abertura de novos cursos do IFSULDEMINAS; a Instrução Normativa n. ${ }^{\circ} 1 / 2018$, da Reitoria/IFTO, que estabelece os procedimentos a serem adotados para autorização, alterações estruturais e conjunturais, aditamentos, suspensão voluntária por tempo determinado, além da extinção/inativação de cursos ofertados pelo IFTO (Instituto Federal do Tocantins) que tramitam pela Pró-Reitoria de Ensino, e dá outras providências; outro que trata da Instrução Normativa da Pró-Reitoria de Desenvolvimento Institucional $n^{\circ} 2$, de 10 de outubro de 2017, que Normatiza os fluxos e procedimentos para a submissão dos Relatórios de Desenvolvimento Institucional para proposta de novos cursos a serem oferecidos pelos campi do IFRS (Instituto Federal do Rio Grande do Sul); e a Instrução Interna de Procedimentos PROENS/ IFPR (Instituto Federal do Paraná) nº 4, de 27 de setembro de 2018, que disciplina sobre os procedimentos de abertura, ajuste, suspensão e extinção de cursos técnicos de nível médio e cursos de graduação nas modalidades presencial e a distância, para o Instituto Federal do Paraná.

Dentre os documentos citados, destacam-se as normativas criadas pelo Instituto Federal do Paraná e Instituto Federal do Rio Grande do Sul, que fazem parte da região sul do país, por tratarem das propostas de aberturas de novos cursos de forma mais detalhada, e este fato justifica escolha desta região para o estudo de caso demonstrado neste estudo.

Outro fato que justifica a escolha pelos documentos produzidos na região sul do país são os dados disponibilizados pela Plataforma Nilo Peçanha (2019), que mostram dados para os anos de 2018 e 2019. Filtrando estes dados por região (Quadro 1), organização acadêmica, modalidade de ensino e tipo de curso e oferta, coletando-se assim os dados disponíveis para cada região do país, do número de cursos técnicos integrados ofertados pelos Institutos Federais, tem-se no quadro abaixo os seguintes dados: 
Quadro 1: cursos técnicos integrados por região: para 2018 e 2019

\begin{tabular}{|l|r|r|r|r|r|r|}
\hline \multirow{2}{*}{ REGIÃO } & \multicolumn{2}{|c|}{ NÚMERO DE CURSOS } & \multicolumn{2}{|c|}{ NÚMERO DE MATRICULAS } & \multicolumn{3}{l|}{ UNIDADES OFERTANTES } \\
\hline & 2018 & 2019 & 2018 & 2019 & 2018 & 2019 \\
\hline SUL & 280 & 329 & 33.206 & 37.026 & 88 & 96 \\
\hline CENTRO - OESTE & 217 & 220 & 22.786 & 24.790 & 62 & 65 \\
\hline NORDESTE & 719 & 757 & 82.371 & 85.574 & 155 & 161 \\
\hline NORTE & 272 & 297 & 26.572 & 27.177 & 59 & 62 \\
\hline SULDESTE & 354 & 393 & 46.209 & 49.149 & 116 & 122 \\
\hline
\end{tabular}

Fonte: Plataforma Nilo Peçanha. (2019).

A partir dos dados coletados calculou-se o aumento e diminuição do número de cursos (Quadro 2), matrículas e unidades de atendimento para cada região, do ano de 2018 para o ano de 2019, para verificar qual região apresentou maior variação no período pesquisado, qual delas abriu mais cursos e ampliou a oferta de cursos técnicos integrados, ponto de interesse para este estudo.

Quadro 2: cursos técnicos integrados: aumento de 2018 para 2019

\begin{tabular}{|l|c|c|c|}
\hline \multirow{2}{*}{ REGIÃO } & NÚMERO DE & NÚMERO DE & UNIDADES \\
CURSOS & MATRICULAS & OFERTANTES \\
\hline SUL & 49 & 3.820 & 3 \\
\hline CENTRO - OESTE & 3 & 2.004 & 6 \\
\hline NORDESTE & 38 & 3.203 & 3 \\
\hline NORTE & 25 & 605 & 6 \\
\hline SULDESTE & 39 & 2.940 & \\
\hline
\end{tabular}

Fonte: Elaborado pelos autores como base nos dados da Plataforma Nilo Peçanha. (2019).

Diante destas informações a região sul foi a que apresentou o maior aumento do número de cursos do ano de 2018 para 2019, com quarenta e nove novos cursos, como também teve o maior número em relação ao aumento de matrículas e do número de unidades ofertantes para o período analisado. Estes dados indicam de a expansão desta oferta educacional está acontecendo e reforçam a escolha da região sul por esta ter contribuindo de forma significativa com este movimento, e estar entre os focos deste estudo que busca principalmente tratar dos documentos que orientam a abertura de novos cursos em especial os técnicos de técnicos integrados.

Esta temática também é aborda no PDI (Plano de Desenvolvimento Institucional) do Instituto Federal do Paraná, ao apontar a necessidade de se desenvolver ações para melhorar as 
propostas de indicação de novos cursos. Neste documento, a instituição traz como uma de suas principais ações o "Incentivo e priorização da abertura de Cursos Técnicos de Nível Médio na forma de oferta integrada" (IFPR, 2014, p. 54). Afirmando ainda que os cursos ofertados devem estar de acordo com as demandas regionais, bem como precisam respeitar os arranjos produtivos sociais e culturais locais, buscando formar para o mundo do trabalho. Fato que justifica a escolha por demonstrar as ações propostas pela Instituição para contribuir com o assunto.

O que também é afirmado no texto da Lei ${ }^{\circ}$ 11.982/2008, que aponta como características e finalidades dos Institutos Federais da Educação orientar sua oferta formativa em benefício da consolidação e fortalecimento dos arranjos produtivos, sociais e culturais locais, identificados com base no mapeamento das potencialidades de desenvolvimento socioeconômico e cultural.

A temática aqui apresentada faz parte da pesquisa intitulada Proposta Metodológica para a abertura de Cursos Técnicos Integrados: uma análise do contexto local/regional, que resultou na dissertação de mestrado profissional em Educação Profissional e Tecnológica (ProfEPT). Pesquisa que teve como intuito colaborar na solução da seguinte problemática: Como superar o desafio da falta de uma metodologia para definição de ofertas de cursos técnicos integrados pela Rede Federal de Educação Profissional e Tecnológica?

\section{PERCURSO METODOLÓGICO}

Para o desenvolvimento deste estudo a metodologia utilizada foi qualitativa, quanto a seus objetivos configura-se como exploratória. Segundo Severino (2007) qualitativa por tratar dos conhecimentos do mundo humano, levando em conta as condições específicas dos sujeitos, exploratória por fazer um levantamento de informações sobre os documentos que orientam o processo de abertura de novos cursos e a existência de uma proposta metodológica para a abertura destes.

Esta pesquisa teve como objetivo apresentar um panorama dos documentos produzidos para nortear o processo de abertura de novos cursos a serem oferecidos pelos Institutos Federais de Educação. Para atingir o objetivo proposto foi feita uma pesquisa documental, para análise das leis e dos documentos que regem a Educação Profissional e Tecnológica ofertada pela Rede Federal de Educação Profissional, buscando analisar os documentos que orientam as propostas de abertura de novos cursos.

Realizou-se um estudo de caso, definido por Severino (2007) como o estudo de um caso particular, significativamente representativo, para mapear os documentos disponibilizados em meio 
eletrônico pelos Institutos Federais da região sul do país, com o intuito de orientar o processo de abertura de novos cursos.

Foi realizada a análise de conteúdos, para levantar e diagnosticar o cenário dos campi do IFPR (Instituto Federal do Paraná) a respeito das ações propostas em seu Plano de Desenvolvimento Institucional, para alcançar o objetivo estratégico de estruturar uma metodologia para a abertura de cursos. Severino (2007) descreve a análise de conteúdos como a metodologia de tratamento e análise de informações em documentos em diferentes linguagens.

As discussões e reflexões em torno do processo de seleção e abertura de novos cursos aportam o desenvolvimento da pesquisa que consubstancia esse estudo, cujo intuito apresentar um panorama dos documentos que norteiam este processo.

\section{RESULTADOS E DISCUSSÃO}

\section{Documentos que norteiam a abertura de novos cursos: em questão os Institutos Federais da região sul do Brasil}

Elencando os documentos que orientam quanto às propostas de criação de novos cursos, a nível nacional em especial para os técnicos integrados fundamenta-se nas Diretrizes Curriculares Nacionais para a Educação Profissional Técnica de Nível Médio, conforme preleciona seu Art. 18 abaixo transcrito:

\footnotetext{
Art. 18 São critérios para o planejamento e a organização de cursos de Educação Profissional Técnica de Nível Médio:

I - atendimento às demandas socioeconômico-ambientais dos cidadãos e do mundo do trabalho, em termos de compromisso ético para com os estudantes e a sociedade;

II - conciliação das demandas identificadas com a vocação e a capacidade da instituição ou rede de ensino, em termos de reais condições de viabilização da proposta pedagógica;

III - possibilidade de organização curricular segundo itinerários formativos, de acordo com os correspondentes eixos tecnológicos, em função da estrutura sócio-ocupacional e tecnológica consonantes com políticas públicas indutoras e arranjos socioprodutivos e culturais locais;

IV - identificação de perfil profissional de conclusão próprio para cada curso, que objetive garantir o pleno desenvolvimento de conhecimentos, saberes e competências profissionais e pessoais requeridas pela natureza do trabalho, segundo o respectivo eixo tecnológico, em função da estrutura sócio-ocupacional e tecnológica e em condições de responder, de forma original e criativa, aos constantes desafios da vida cidadã e profissional (BRASIL, 2012, p.5).
}

Destacando neste estudo principalmente o critério referente atendimento às demandas socioeconômico e ambientais dos cidadãos e do mundo do trabalho, e o compromisso ético para 
com os estudantes e a sociedade, surge a seguinte problemática: os documentos orientadores conseguem identificar as demandas socioeconômicas e ambientais de uma determinada localidade, corroborando a abertura de novos cursos?

Outro documento que trata do assunto é a Lei de Criação da Rede Federal Lei $n^{\circ}$ 11.982/2008, afirmando em seu Art. $6^{\circ}$ que os Institutos Federais têm como finalidade e característica:

I - ofertar educação profissional e tecnológica, em todos os seus níveis e modalidades, formando e qualificando cidadãos com vistas na atuação profissional nos diversos setores da economia, com ênfase no desenvolvimento socioeconômico local, regional e nacional; II - desenvolver a educação profissional e tecnológica como processo educativo e investigativo de geração e adaptação de soluções técnicas e tecnológicas às demandas sociais e peculiaridades regionais;

III - promover a integração e a verticalização da educação básica à educação profissional e educação superior, otimizando a infra-estrutura física, os quadros de pessoal e os recursos de gestão;

IV - orientar sua oferta formativa em benefício da consolidação e fortalecimento dos arranjos produtivos, sociais e culturais locais, identificados com base no mapeamento das potencialidades de desenvolvimento socioeconômico e cultural no âmbito de atuação do Instituto Federal; (BRASIL. 2008)

No texto desta lei destaca-se que a oferta, ou seja, a escolha e a indicação dos cursos a serem ofertados devem acontecer com ênfase no desenvolvimento socioeconômico local, regional e nacional, indicado com base nas potencialidades da região, por meio do mapeamento do desenvolvimento socioeconômico e cultural. E apresenta-se mais um questionamento: quais documentos norteiam os mapeamentos indicados pela lei? Evidenciando ainda outro ponto tratado neste documento que é a verticalização de tais cursos.

A questão da verticalização da educação profissional é discutida também no Decreto $\mathrm{n}^{\mathrm{o}}$ 9.235/2017, que na sua Seção VIII, Art. 40 no $§ 3^{\circ}$ - que trata da autorização de cursos, afirma:

$\S 3^{\circ}$ As instituições da Rede Federal de Educação Profissional, Científica e Tecnológica somente poderão ofertar bacharelados e cursos superiores de tecnologia nas áreas em que ofereçam cursos técnicos de nível médio, assegurada a integração e a verticalização da educação básica à educação profissional e educação superior. (BRASIL. 2017).

O Decreto evidencia de forma mais latente o processo de indicação de um curso técnico de nível médio, que necessita se pautar em documentos que orientem estas escolhas para que estes se estabeleçam em beneficio da sociedade e do desenvolvimento local/regional. Lembrando que a verticalização dos cursos dependerá destas indicações.

E por último vislumbra-se o Catálogo Nacional de Cursos Técnicos, definido pelo Ministério da Educação (2019) como:

um instrumento que disciplina a oferta de cursos de educação profissional técnica de nível médio, para orientar as instituições, estudantes e a sociedade em geral. É um referencial 
para subsidiar o planejamento dos cursos e correspondentes qualificações profissionais e especializações técnicas de nível médio. (BRASIL, 2019).

Documento que dá todo suporte para a escolha e indicação de novos cursos, embora não trate do processo que leva a escolha de um eixo e/ou curso, é um documento de suma importância para este momento.

Partindo então para os documentos produzidos pelas instituições Federais de Educação, realizou-se um estudo de caso, para levantar e demonstrar os documentos produzidos pelos IF da região sul de nosso país, destinados a orientar a criação de novos cursos, buscando verificar a existência de instrumentos que fossem especificamente para os cursos técnicos integrados.

A região sul é composta por três estados, segundo a Plataforma Nilo Peçanha (2019) são seis Institutos Federais. No Rio Grande do Sul tem-se o IFFARROPILHA (Instituto Federal Farroupilha), o IFRS (Instituto Federal do Rio Grande do Sul) e o IFSUL (Instituto Federal Sul-riograndense), em Santa Catarina o IFC (Instituto Federal Catarinense) e IFSC (Instituto Federal de Santa Catarina) e no Paraná o IFPR (Instituto Federal do Paraná).

Este estudo de caso concretiza uma investigação para averiguar se tais instituições dispõem de uma proposta metodológica específica que oriente e regulamente o momento de escolha e indicação de um curso, em especial os cursos técnicos integrados. Ressalta-se que o intento também se propõe a verificar se esta indicação desenvolve suas ações buscando o desenvolvimento regional e local, como disciplina a lei de criação dos Institutos.

Para isto foi realizada uma pesquisa no site das instituições acima citadas, selecionando documentos como Plano de Desenvolvimento Institucional, Instruções Normativas Internas, Sistema e Relatório de Indicadores para análise, a fim de que se percebesse haver (ou não haver) indicações que regulamentassem a criação de novos cursos.

Iniciaram-se as buscas documentais por Santa Catarina, haja vista que no estado são dois Institutos Federais de Educação, o IFSC e o IFC. Começando a análise pelo IFC (Instituto Federal Catarinense), verifica-se que o Plano de Desenvolvimento Institucional da instituição (2014) trata da oferta de educação em todos os níveis, afirmando a busca do atendimento das demandas regionais. Neste documento estabeleceu-se como um objetivo estratégico: criar uma política para a implantação gradativa de novos cursos. Afirmando que cada campus tem a autonomia de oferecer cursos à comunidade baseando-se em seus Arranjos Produtivos Locais (APLs). Nas buscas realizadas não foi encontrado nada que se indica as ações para atingir tal objetivo. Outrossim, importante salientar que dos documentos que são disponibilizados pelo IFC (Instituto Federal 
Catarinense) para consulta pública, não foi encontrado nenhum instrumento que oriente a proposta de abertura de novos cursos, em especial para os técnicos integrados.

A outra instituição que oferece educação profissional pela rede Federal de Educação é o IFSC (Instituto Federal de Santa Catarina), cujo Plano de Desenvolvimento Institucional (2015) destaca a pretensão de intensificar as atividades de pesquisa aplicada, desenvolvimento tecnológico e inovação em articulação com o setor produtivo e para isso indicou que implantaria nos próximos cinco anos um Polo de Inovação, destinado ao atendimento de demandas das cadeias produtivas.

Apontado como um grande desafio para o IFSC garantir um ensino profissional e tecnológico para todos e de qualidade, em consonância com os arranjos produtivos, grupos sociais e manifestações culturais locais, afirma-se que as demandas locais devem sempre estar presentes nos planos de novas ofertas e por isso os arranjos produtivos locais devem ser sempre uma fonte de informação para a oferta educativa.

Quanto à abertura de novos cursos no Plano de Desenvolvimento Institucional do IFSC indicou como um de seus objetivos: estruturar a oferta de cursos com base em estratégia, não detalhada no documento, para implantar e otimizar processos para a adequação da oferta de cursos, de modo a reduzir a evasão, aumentar a inserção profissional e ampliar o impacto social da instituição.

O IFSC conta ainda como indicador a implantação anual do Plano de Oferta de Cursos e Vagas, documento elaborado para nortear a instituição em suas decisões acerca da oferta de cursos, da admissão de professores e da ampliação de espaço físico. Estes documentos pouco falam do processo de abertura de novos cursos e de quais dados, fontes e atores devem ser ouvidos neste momento.

No estado do Paraná encontra-se como representante dos Institutos Federais o IFPR (Instituto Federal do Paraná). Em análise ao seu Plano de Desenvolvimento Institucional, ficou clara a proposta da Instituição em construir sua ação educativa em parceria com a sociedade como um todo. Neste documento norteador são apontados objetivos estratégicos, e os pontos fortes e fracos da instituição. Interessante notar que um dos pontos fracos da instituição é a "falta de uma metodologia adequada para definição de ofertas de cursos”. (IFPR, 2014, p.172).

Em nível institucional o IFPR já contou com quatro normativas internas para nortear o assunto. A primeira delas foi a Instrução Interna de Procedimentos PROENS/IFPR n ${ }^{\circ} 18$, de 15 de dezembro de 2011, que normatizava os procedimentos de abertura de Cursos Técnicos de Nível Médio nas modalidades presencial e a distância do IFPR. Tratando em se Art. $1^{\circ}$ da proposta de abertura de novos cursos preleciona: 
$1^{\circ}$ A proposta de novos cursos deve seguir do debate com a comunidade substanciada em indicadores que retratem a realidade, considerando a demanda dos arranjos produtivos, culturais e sociais, incluindo um mapeamento da realidade regional, levantando os dados e apresentando as justificativas da proposta de cursos para a submissão do coletivo do Campus e Conselho Diretor do Campus para elaboração do Projeto Pedagógico do Curso (IFPR, 2011, p.1).

Documento que foi substituído pela Instrução Interna de Procedimentos PROENS/IFPR $\mathrm{n}^{\circ}$ 1, de 22 de junho de 2016, que regulamentava a oferta de cursos regulares no âmbito do IFPR. No Art. $4^{\circ}$ dizia que:

$4^{\circ}$ As propostas de novos cursos devem estar em consonância com o Plano de Desenvolvimento Institucional (PDI), com o Projeto Político Pedagógico do campus (PPP), a legislação educacional vigente, com o Eixo Tecnológico ou Área de Conhecimento, e de nomenclatura de curso. (IFPR, 2016, p.2-3).

No Art. $5^{\circ}$ deste mesmo documento, salientava-se que a proposta de novos cursos deveria estar relacionada ao campus proponente e sua região, e apresentar os seguintes elementos elencados no inciso desse caput:

I - planejamento anual de ações e recursos do campus;

II - itinerários Formativos do campus;

III - arranjos produtivos e demanda sociais e regionais, comprovadas por meio de dados obtidos em fontes reconhecidas e que justifique a necessidade do curso;

IV - diagnósticos resultantes de consultas públicas e reuniões com a comunidade interna e externa;

$\mathrm{V}$ - potenciais para indução de formação em áreas prioritárias, conforme Lei $\mathrm{n}^{\circ} 11.892$, de 29 de dezembro de 2008 , independente da demanda pública existente, de acordo com a missão do IFPR (IFPR, 2016, p.3).

O documento acima citado foi substituído pela Instrução Interna de Procedimentos PROENS/IFPR n ${ }^{\circ}$ 2/2017, que dispõe sobre a oferta de cursos técnicos de nível médio e cursos de graduação no âmbito do IFPR. O Art. $6^{\circ}$ e incisos afirma que os novos cursos devem estar de acordo com:

I - a legislação vigente;

II - o Estatuto do IFPR;

III - o Plano de Desenvolvimento Institucional (PDI);

IV - as normativas institucionais;

V - o Projeto Político Pedagógico do campus (PPP);

VI - o Catálogo Nacional de Cursos Técnicos de Nível Médio;

VII - o Catálogo Nacional de Cursos Superiores de Tecnologia;

VIII - o Catálogo Brasileiro de Ocupações (CBO);

IX - o planejamento anual de ações e recursos do campus;

$\mathrm{X}$ - o itinerário formativo do campus;

$\mathrm{XI}$ - os arranjos produtivos e demandas sociais locais e regionais, comprovados por meio de dados obtidos em fontes reconhecidas, e que justifiquem a necessidade do curso;

XII - as condições de empregabilidade para os egressos;

XIII - os diagnósticos resultantes de consultas públicas e reuniões com a comunidade interna e externa;

XIV - os potenciais para indução de formação em áreas prioritárias, conforme a Lei $\mathrm{n}^{\mathrm{o}}$ 11.892, de 29 de dezembro de 2008. (IFPR, 2017, P.3). 
Em 2018, O IFPR publicou a Instrução Interna de Procedimentos PROENS/ IFPR no 4, de 27 de setembro de 2018, normativa que atualiza e define critérios para abertura de novos cursos, para implantação a partir do ano de 2020. Esta versão atualizada traz mais informações sobre os encaminhamentos para a proposta de abertura de um curso, tratando no seu Capítulo II da abertura de cursos, afirmando que:

\footnotetext{
Art $5^{\circ} \mathrm{A}$ abertura de novos cursos no IFPR envolverá as seguintes etapas:

I - Elaboração e apreciação da Proposta de Abertura de Cursos;

II - Elaboração e apreciação do Projeto Pedagógico do Curso;

III - Criação do Curso;

IV - Autorização de Funcionamento do Curso (BRASIL, 2018).
}

Salienta-se que a maior para este estudo o que diz respeito a proposta de abertura de cursos. Além do que já previa o documento de 2017, esta normativa define que as propostas de novos cursos devem estar em consonância com o Decreto 9.235/2017, como também deve atender às condições orçamentárias, às de recursos humanos e de infraestrutura dos campi e o itinerário formativo do campus. Ressalta-se nessa normativa anteriormente mencionada que os arranjos produtivos e demandas sociais locais e regionais devem ser comprovados por meio de dados obtidos em fontes reconhecidas, que justifiquem a necessidade do curso, embora não faça nenhuma indicação de quais dados e fontes poderiam colaborar nesta justificativa.

Todos os documentos salientam que a indicação de um curso deve pautar-se no debate como a comunidade e no estudo da demanda local, subsidiado por indicadores dos arranjos produtivos, culturais e sociais. Um ponto que será detalhado neste estudo é a inclinação do IFPR em buscar estruturar uma proposta metodológica para abertura de novos cursos. A instituição conta com uma instrução normativa para nortear a oferta de todos os cursos. Não foi encontrado, contudo, nenhum documento vigente que tratasse especificamente da abertura dos cursos técnicos integrados.

Partindo para análise dos documentos produzidos pelos Institutos Federais do Rio Grande do Sul, verificou-se que as pesquisas realizadas no PDI do IFSul (Instituto Federal Sul-rio-grandense) (2014, p.21) apontou como um desafio a interação entre a instituição e os arranjos produtivos locais, colocando como o principal objetivo da instituição ofertar educação que contribua para melhoria da qualidade de vida da população. Consta como objetivos estratégicos e metas para o período de 2014 a 2019 (p.26) “fortalecer o IFSul como instituição educacional pública transformadora da realidade social", enfatizando a "Meta 2.22: Vincular cada campus a, no mínimo, um arranjo produtivo local na sua região de abrangência”.

Diante de tal meta, percebeu-se que a instituição busca atender aos arranjos produtivos locais, bem como desenvolver suas ações em parceria com a comunidade. A instituição para o 
fortalecimento dos arranjos produtivos, sociais e culturais locais, adotou também como política de aproximação e interação com o mundo do trabalho do entorno de cada campus e reitoria, visitas gerenciais e visitas técnicas (BRASIL, 2014, p.48).

A instituição conta ainda com outros dois documentos institucionais que foram analisados, um deles é o Sistema de Indicadores para o acompanhamento e monitoramento do Plano De Desenvolvimento Institucional, e o outro é o Relatório de Indicadores de 2017, organizados para apresentar os resultados apurados pela instituição, funcionando como uma avaliação qualitativa da gestão do IFSul feita a partir dos objetivos estratégico estabelecidos.

Foi constatado com a leitura destes documentos que o IFSul desenvolve suas ações voltadas para o fortalecimento dos arranjos produtivos, sociais e culturais locais. Quanto a uma proposta metodológica para a abertura de novos cursos, não foi encontrado nenhum documento que trata especificamente do assunto.

Em estudo ao PDI do IFFarroupilha (2014), destacam-se as finalidades da criação dos Institutos, indicando a intenção de orientar sua oferta formativa em benefício da consolidação dos arranjos produtivos, sociais e culturais locais, que devem ser identificados com base no mapeamento das potencialidades. Estando entre uma de suas concepções Políticas Pedagógicas a indissociabilidade das ações de ensino, pesquisa aplicada e extensão para o desenvolvimento socioeconômico local e regional, também é previsto o estabelecimento de parcerias com os setores produtivos e demais instituições da sociedade civil. Percebe-se com os dados levantados que a instituição busca consolidar a oferta de seus cursos para o desenvolvimento dos arranjos produtivos locais como prevê a legislação. Nada foi encontrado entre os documentos disponibilizados pela instituição referente a uma proposta metodológica para a abertura de novos cursos.

Ao analisar o PDI (2014) do IFRS (Instituto Federal de Educação, Ciência e Tecnologia do Rio Grande do Sul), evidenciou-se como uma das ações fundamentais dessa instituição o compromisso com a oferta formativa em benefício da consolidação e fortalecimento dos arranjos produtivos, sociais e culturais locais, identificados com base no mapeamento das potencialidades de desenvolvimento socioeconômico e cultural. Entretanto, não foram elencadas ações específicas para se atingir tal objetivo.

Naquilo que tange a uma metodologia para a abertura de novos cursos, o IFRS conta com a Instrução Normativa da Pró-Reitoria de Desenvolvimento Institucional $n^{\circ}$ 2, de 10 de outubro de 2017, que normatiza os fluxos e procedimentos para a submissão dos Relatórios de Desenvolvimento Institucional para proposta de novos cursos a serem oferecidos por seus campi. Vale destacar que esse é o documento que mais se aproxima da proposta de se adotar uma 
metodologia para abertura de novos cursos, com a indicação de dados, fontes e atores mínimos a serem considerados durante este processo.

Este documento em seu anexo I trata das: Orientações para Elaboração do Relatório de Desenvolvimento Institucional de Cursos Regulares, Programas Específicos e Educação a Distância. Detalhando alguns pontos mínimos que devem ser contemplados para a abertura de novos cursos.

Em análise a Instrução Normativa do IFRS (2017), constatou-se que segundo este documento se faz necessário a indicação da Relevância do Curso, a ser comprovada por meio de vários dados e informações.

O documento trata ainda de outros assuntos importantes para se pensar e planejar a abertura de um novo curso, como a pesquisa com a comunidade externa, ouvindo órgãos públicos, empresas e entidades em geral. Indicando como uma necessidade a escuta da sociedade em geral, para que os cursos ofertados não contemple apenas um setor, que geralmente acaba por servir as necessidades do mercado de trabalho.

Propõe-se nesta instrução normativa (2017) a construção de um quadro de indicadores regionais, para se caracterizar o perfil socioeconômico da região, a ser comprovado por órgãos oficiais, indicando alguns órgãos para consulta e embasamento, mas sem detalhar quais dados devem ser considerados, estes são voltados para a região do Rio Grande do Sul.

Outra importante informação levantada na normativa é a descrição do benefício social e a contribuição para o desenvolvimento regional do curso a ser ofertado, apontando os arranjos produtivos não apenas os econômicos mais também os sociais e culturais estabelecendo relação destes como os cursos a serem ofertados.

A verticalização também se mostra como uma das preocupações da instituição neste documento. Apontando-se ainda como uma ação importante fazer uma pesquisa dos cursos já disponibilizados na região, buscando-se evitar a oferta de cursos similares pelo Instituto.

De todos os documentos analisado este foi o que realizou uma abordagem mais detalhada do processo de escolha e indicação de novos cursos, percebeu-se a intenção da instituição em padronizar estas propostas, bem como estabelecer pontos mínimos a serem levantados e considerados neste momento.

Observou-se que todas as instituições têm indicações de buscar a abertura de novos cursos tendo em vista a oferta de uma educação de qualidade que fortaleça o desenvolvimento local e regional. Porém são poucos os documentos que norteiam este processo, sendo pequeno o número de 
documentos produzidos especificamente para tratar da criação e oferta de novos cursos, menos ainda do processo que leva a essa indicação.

\section{O Instituto Federal do Paraná frente ao objetivo de estruturar uma metodologia para a} abertura de novos cursos uma análise ao PDI (2014/2018) institucional

Diagnosticar o cenário atual dos campi do IFPR a respeito da elaboração de uma metodologia para abertura de cursos se apresenta como um dos objetivos propostos neste estudo, para atingir este fim foi feita uma análise ao PDI da instituição.

Os Institutos Federais foram criados pela Lei $n^{\circ}$ 11.892/2008, desde então o número de Institutos Federais só tem crescido. Esta expansão passa necessariamente pela a abertura de novos cursos, e no IFPR não tem sido diferente este movimento.

Nesta perspectiva objetivou-se fazer uma investigação de como os campi do IFPR tem avançado e desenvolvido ações visando a estruturação de uma metodologia para abertura de novos cursos. Fez-se um recorte buscando principalmente averiguar o que foi produzido para os cursos técnicos integrados no período entre 2014 e 2018, fazendo uma análise ao PDI da Instituição.

O IFPR conta com vinte e cinco campi espalhados pelo estado do Paraná e continua em expansão, como pode ser observado na figura 1 .

\section{FIGURA 1 - Localização dos campi do IFPR}

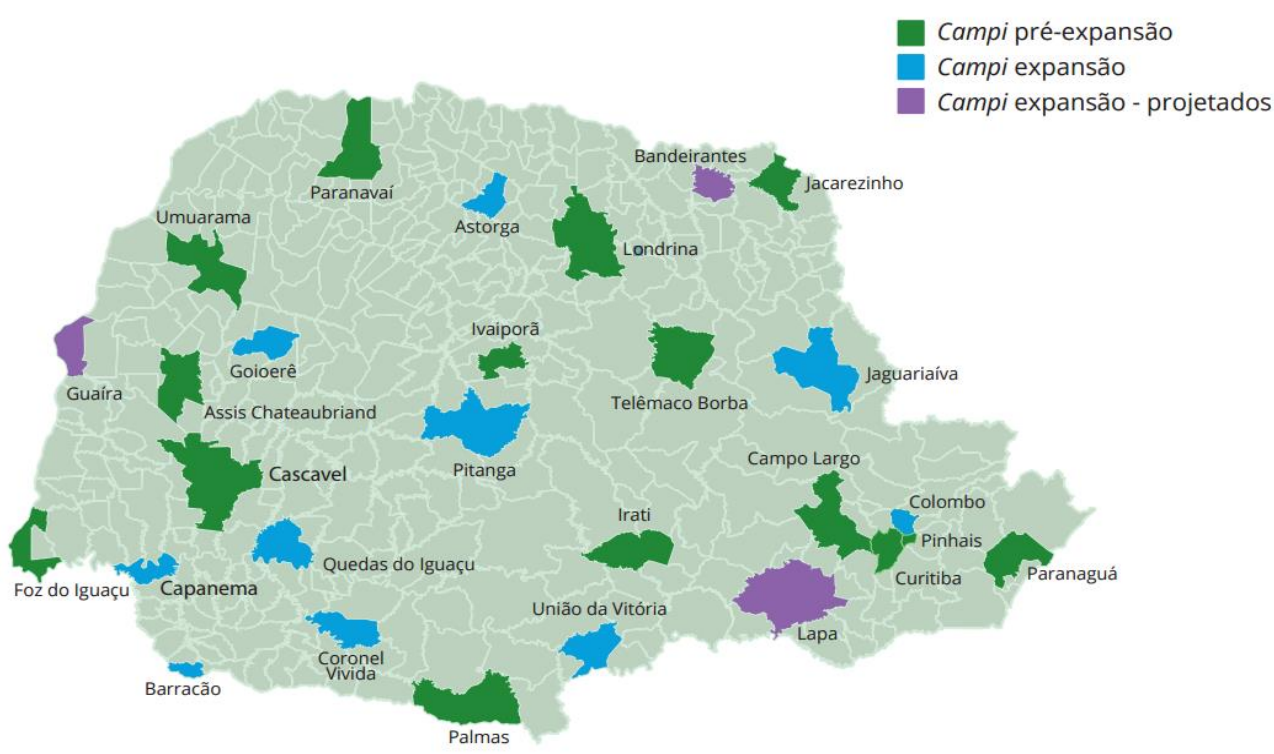

Fonte: IFPR (2018). 
Estando presentes nas cidades: Assis Chateaubriand, Campo Largo, Cascavel, Curitiba, Foz do Iguaçu, Irati, Ivaiporã, Jacarezinho, Londrina, Palmas, Paranaguá, Paranavaí, Telêmaco Borba, Umuarama. Também está em fase de implantação nas cidades: Pinhais, Pitanga, União da Vitória, Jaguariaíva, Colombo, Capanema. Vinculadas aos campi, o IFPR estarão nos municípios: Astorga, Goioerê, Quedas do Iguaçu, Coronel Vivida, Barracão, Bandeirantes, Guaíra e Lapa. (IFPR, 2018),

O IFPR contava com o PDI (2014/2018), documento elaborado coletivamente por técnicoadministrativos, professores, estudantes e representantes da sociedade visto como uma ferramenta de gestão que direciona a Instituição no que diz respeito à sua filosofia de trabalho, missão, seus objetivos estratégicos e as diretrizes pedagógicas para todos os campi. (IFPR, 2014, p.13).

A Instituição afirmava neste documento acreditar na possibilidade de construir uma sociedade mais igualitária e fraterna, investindo na participação da sociedade e dos representantes do mercado de trabalho como forma de formar cidadão críticos e conscientes. Propondo pautar e executar suas atividades na:

\begin{abstract}
articulação com a sociedade e com representantes do mercado de trabalho certamente trará, ao processo educativo e formativo, valiosa contribuição em relação à compreensão dos valores sociais do trabalho e da dignidade da pessoa humana. Isso é essencial ao processo educacional que se munirá de condições de despertar nas pessoas a consciência cidadã voltada para a compreensão da realidade social em que vivem e a importância da participação no processo de transformação desta realidade, para que se possa construir uma sociedade mais livre, igualitária, justa, fraterna, solidária e soberana. (IFPR, 2014, P.25).
\end{abstract}

Baseando-se nos apontamentos descritos no PDI, este estudo buscou investigar se está parceria com a sociedade e busca da transformação da realidade, estava presente nas ações quando se propõe a aberturas de novos cursos técnicos integrados.

O quadro 3 apresenta um recorte do quadro de desdobramento dos eixos estratégicos, apresentado no PDI do IFPR, que indicou no eixo estratégico: Ensino, Pesquisa, Extensão e Inovação, o objetivo de número 015 estruturar metodologia para a abertura de novos cursos. Sendo sobre este eixo as próximas considerações apontadas.

Na edição 2014-2018 do PDI foram feitas revisões dos objetivos estratégicos de cada campus, estes foram demonstrados por meio de quadros que detalham todos os objetivos estratégicos a serem atingidos. Neste texto elencaram-se apenas os objetivos, estratégias, projetos/ação, responsável, data de início e fim e os investimentos, previstos para alcançar a diretriz organizacional: Indução à criação de áreas de referência para a oferta de cursos, e o objetivo: Estruturar metodologia para a abertura de novos cursos. 


\section{Quadro 3: eixo estratégico / diretrizes / objetivos}

\begin{tabular}{|c|c|c|}
\hline EIXO ESTRATÉGICO & $\begin{array}{l}\text { PLANEJAMENTO ESTRATEGIC } \\
\text { DIRETRIZES ORGANIZACIONAIS }\end{array}$ & $\frac{\text { OO IFPR - } 2014 / 2018}{\text { OBIETIVOS ESTRATÉtGICOS }}$ \\
\hline $\begin{array}{l}\text { ENSINO, PESQUISA, } \\
\text { EXTENSÃO E INOVAÇĂ̈O }\end{array}$ & 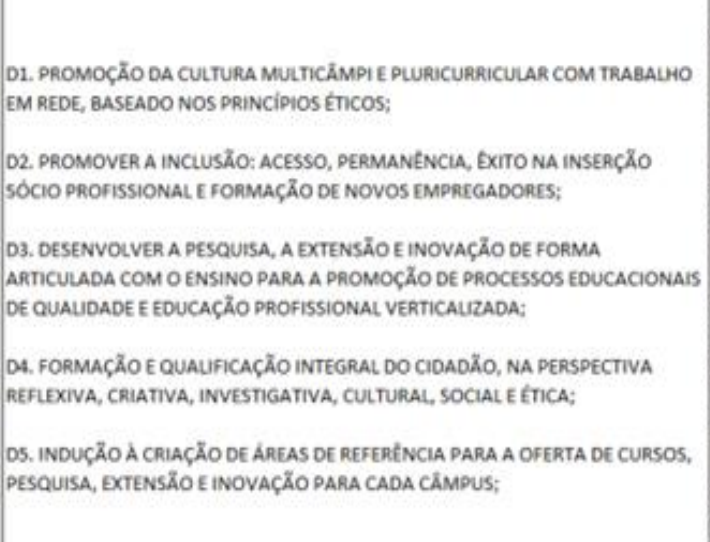 & 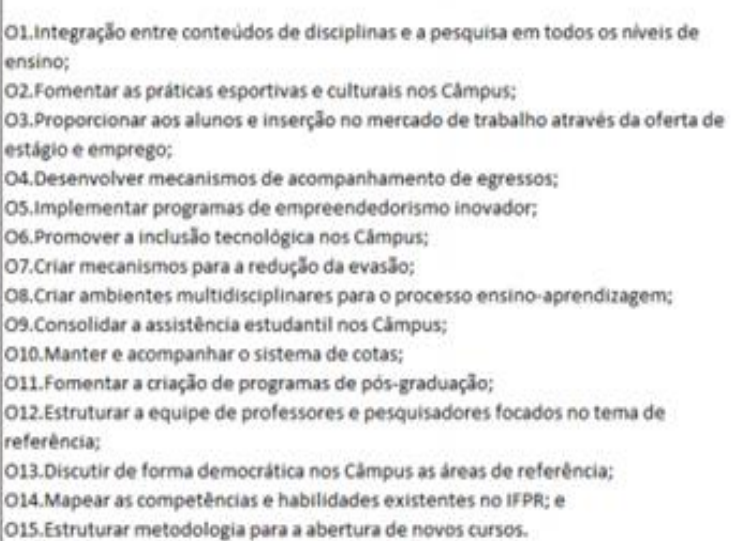 \\
\hline
\end{tabular}

Fonte: PDI IFPR (2014/2018).

Nos próximos parágrafos apresentou-se as ações que cada campus do IFPR indicou nesta perspectiva, em especial buscou-se fazer um mapeamento das ações propostas em relação a abertura de cursos técnicos integrados.

O Campus Assis Chateubriand, não indicou nenhuma ação especificamente relacionada à abertura de cursos, propondo como objetivo em comum identificar as necessidades e oportunidades da instituição, para equalizar a realidade do campus as demandas existentes.

O Campus Campo Largo indicou como ação atualizar o diagnóstico da instituição e elaborar um estudo de viabilidade, prevendo este como estratégia de planejamento e estudos para ampliação da oferta de cursos, sendo os responsáveis por estas ações a Direção Geral e a Direção de Ensino, Pesquisa e Extensão a serem realizadas entre os anos de 2016 e 2018.

Já o Campus Capanema definiu como estratégia promover uma normatização para a abertura de cursos com base nas normas existentes, organizando para isso um Grupo de Trabalho para a elaboração de normativas para a abertura de novos cursos, que deveria ser aprovado pelo CODIC (Colégio Dirigente do Campus) e Direção Geral, tendo como responsáveis a Direção Geral e os servidores, previstas para realização no ano de 2017.

O Campus Cascavel trouxe como estratégia verificar as possibilidades de ampliar a oferta de cursos no campus, como ação indicou a elaboração de um estudo para confirmar tal viabilidade, tendo como responsáveis a Direção de Ensino, Pesquisa e Extensão, com previsão para ser realizado entre junho de 2016 e dezembro de 2018. 
O Campus Colombo propôs como objetivo criar procedimentos para a abertura de novos cursos, não especifica que tipo de curso, buscando como estratégia desenvolver procedimentos e fluxos por meio de discussões no campus, propõe que estas ações são da responsabilidade da Direção Geral e Direção de Ensino, Pesquisa e Extensão, prevista para finalização até o segundo semestre de 2018.

O Campus Curitiba apresentou como objetivo criar Grupos de Trabalhos por área de conhecimento para saber a necessidades de novos cursos de especialização especificamente, fazendo reuniões bimestrais, prevendo como estratégia realizar estudos com empresas e instituições públicas e privadas para se verificar a necessidade e um determinado tipo de profissional, tendo como responsável a Direção de Ensino, a ser realizado no ano de 2016, não indicando nenhuma ação para os cursos técnicos integrados.

O Campus Foz do Iguaçu indicou como objetivo criar Parâmetros para a abertura de novos cursos, por meio de uma Comissão, com reuniões bimestrais, tendo como responsável os membros da comissão instituídos pela Portaria 59/2015, com previsão de início em fevereiro de 2016 e fim em dezembro de 2018.

O Campus Irati propôs como objetivo padronizar as ações a serem desenvolvidas pelo campus, estabelecendo fluxogramas internos, adicionando ações que não estão previstas nos documentos norteadores do IFPR, descrevendo como algumas de suas ações: avaliar as pesquisa de demanda, levantamento de custos, estratégias para conter a evasão, bem como avaliar os APL (Arranjos Produtivos Locais) e cenário dos cursos ofertados que fazem concorrência com a instituição, sendo os responsáveis por estas ações Direção-Geral, DIEPEX (Direção de Ensino Pesquisa e Extensão), e DIPLAD (Diretoria de Planejamento e Administração), a serem realizadas no ano de 2017.

O Campus Ivaiporã objetiva criar cursos que atendam os interesses e a da demanda do município, investigando por meio de pesquisa a demanda, como ação prevê a aplicação de questionários nas escolas e realizar reunião com gestores e representantes da comunidade, dentre as ações indicadas não faz menção aos cursos técnicos integrados.

O Campus Jacarezinho indicou como objetivo estudar a viabilidade de novos cursos, promovendo discussões dentro do CGCP (Colegiado de Gestão Pedagógica do Campus), criando núcleos docentes estruturantes, bem como estudo junto a comunidade externa por meio de consulta pública, indicando a Direção de Ensino, Pesquisa e Extensão como responsáveis, a serem realizadas entre os anos de 2016 e 2018. 
O Campus Jaguariaíva indicou como objetivo consolidar o curso técnico de Ensino Médio em Biotecnologia buscando como estratégia a implantação do PPC (Projeto Pedagógico de Curso), tendo como ação criar uma comissão para criação do curso médio integrado, sendo os responsáveis a Direção-Geral e DIEPEX (Direção de Ensino Pesquisa e Extensão), ações para os anos de 2016 e 2017.

O Campus Londrina pretendia estruturar uma metodologia embasada nas orientações institucionais tendo como responsável Direção-Geral e de Ensino, com previsão de execução para o ano de 2017 e 2018.

O Campus Palmas apresentou como objetivos abrir novos cursos de acordo com as necessidades locais, tendo como estratégia a definição de padrões internos e fluxograma para isto prevê como ação a realização de pesquisa de demanda, indica como responsável a Direção Geral e a Direção de Ensino, Pesquisa e Extensão, a serem realizadas no período de fevereiro de 2017 a dezembro de 2018.

O Campus Paranaguá indicou como objetivo mapear as demandas locais, fazendo um levantamento com escolas municipais, estaduais e privadas, levantando as necessidades e buscando ofertar cursos que estejam de acordo com a demanda social e profissional da região, prevendo como ação realizar reuniões no início do ano, fazendo levantamento de estudos para propor novos cursos emitindo relatório sobre o parecer, indicando como responsável a Diretoria de Ensino, ações a serem realizadas no período e fevereiro de 2016 a dezembro de 2018.

O Campus Paranavaí propôs como objetivo estruturar uma metodologia para abertura de novos cursos no Campus, tendo como estratégia elaborar uma instrução normativa interna, buscando como ação uma proposta de metodologia/regras para abrir novos cursos tomando por base as instruções da Pró-Reitoria de Ensino, indicando como responsáveis a Coordenação de Ensino e Direção de Ensino, durante o primeiro semestre de 2016.

Pinhais trazia como objetivo a identificação de cursos a serem ofertados consultando a comunidade os órgãos patronais e trabalhadores, tendo por finalidade atender a demanda regional, indicando como responsáveis por estas ações a Direção Planejamento e Administração, CODIC, (Colegiados de Cursos) e NUTEAD (Núcleo de Tecnologia e Educação a Distancia), no período de agosto de 2016 a dezembro de 2018, prevendo um investimento de $\mathrm{R} \$ 2.000,00$.

O Campus Pitanga indicou como objetivo definir uma metodologia coerente para a abertura de novos cursos, prevendo como estratégia identificar a demanda regional, e buscar estudos para verificar a viabilidade de abertura de um curso no eixo tecnológico do campus e outro em outro eixo, listando como ações a aplicação de questionários e pesquisa de campo com o público alvo, 
criação e um grupo de estudo para elaborar a proposta por conta da Direção-Geral, Direção de Ensino, Pesquisa e Extensão e Coordenação de Curso da área de ensino - ações a serem realizadas de março de 2017 a dezembro de 2018, prevendo um investimento de $\mathrm{R} \$ 10.000,00$.

O Campus Telêmaco Borba apontou como objetivo a definição consistente da estruturação e metodologia para a abertura de novos cursos, para atingir este objetivo o campus indicou como estratégia promover diálogos e reuniões pretendendo fazer uma análise de dados a respeito da longevidade do curso, para então poder realizar investimentos e contratações de servidores, que possam colaborar na otimização do processo pedagógico, definiu como período para executar estas medidas entre janeiro de 2016 a dezembro de 2018, indicando como responsáveis além da Direção de Ensino Pesquisa e Extensão a Direção de planejamento.

O Campus Umuarama ditava como objetivo a criação de uma comissão para promover estudos de viabilidade de cursos, prevendo reuniões bimestralmente que deveriam ser realizadas até o final de janeiro de 2016, afirmando que os planejamentos das propostas devem ser baseados em indicadores internos e externos, bem com levar em conta a gestão de pessoas e a demanda regional, sendo responsável por estas ações a Direção de Ensino.

O Campus União da Vitória apostava na realização de audiências públicas, nas reuniões com representantes da sociedade, envolvendo os arranjos produtivos locais, bem como realizar pesquisas de demanda e análise socioeconômica da região, ações a serem realizadas entre fevereiro de 2016 e dezembro de 2018, apontando como responsáveis a Direção-Geral e de Ensino.

Não se tem dados das ações previstas para os campi de Astorga, Barracão, Coronel Vivida e Quedas do Iguaçu, dentre os quadros apresentados na versão do PDI analisado, o Campus Goioerê aparece no documento, porém não faz menção ao objetivo de buscar estruturar uma metodologia para a abertura de novos cursos, diante deste fato as análises para estas instituições não constam neste estudo.

Elencando-se as ações mapeadas no PDI, pode-se constatar que as estratégias indicadas pelos campi para estruturar uma proposta metodológica para a abertura de novos cursos são: i. elaboração de estudos de viabilidade; ii. a criação de procedimentos de fluxos; iii. elaboração de parâmetros; iv. instituição de comissões; v. promoção de normatização com base nas normas existentes; vi. estabelecimento de fluxogramas internos adicionando ações que não estão previstas nos documentos norteadores do IFPR; vii. avaliação dos APL; viii. pesquisa da demanda municipal; ix. aplicação de questionário com o público alvo dos cursos; x. conversas com gestores e representantes da comunidade; xi. elaboração de normativas internas; xii. definição de metodologia 
coerente; xiii. busca pela identificação da longevidade do curso; xiv. diálogos, reuniões e audiências públicas.

Em pesquisas ao site dos campi do IFPR, apesar das indicações elencadas no PDI da instituição, nenhum documento publicado foi encontrado, além das Instruções Internas Normativas e das Diretrizes Curriculares Nacionais que tratem do assunto e que foram mencionadas nesse estudo.

\section{CONSIDERAÇÕES FINAIS}

De acordo com Turmen e Azevedo (2017, p. 1074), nota se que há um esforço do Estado em ampliar a oferta de matrículas e interiorizar a educação pública federal, com a criação dos IF e ampliação dos campi, em Estados até então excluídos de efetivas políticas públicas em educação profissional e tecnológica.

$\mathrm{Na}$ busca em efetivar uma das finalidades dos IF - a oferta de uma educação profissional pública e de qualidade, a abertura de novos cursos certamente colaborará com a expansão da Rede Federal, pensado como movimento que deve acontecer de forma planejada em benefício do desenvolvimento local e regional.

Diante do panorama apresentado neste estudo pode-se afirmar que são poucos os documentos que orientam e disciplinam os processos e procedimentos de criação e abertura de novos cursos, em particular os técnicos integrados. Outro ponto, é que as instituições têm o grande desafio de atender a lei, na busca pelo atendimento às demandas socioeconômicas e ambientais dos cidadãos e do mundo do trabalho.

De acordo com as buscas feitas, as instituições contam com as orientações das Diretrizes Curriculares Nacionais para Educação Profissional Técnica Nível Médio, como a Lei n. 11.892/08 que institui a Rede Federal de Educação, com o Decreto n. 9.235/2017 e com o Catálogo Nacional de Cursos Técnicos, além de alguns documentos institucionais como as normativas internas.

Com o estudo de caso realizado para a região sul do país, verificou-se que há poucas instruções normativas internas que tratam das propostas de abertura de novos cursos, destacam-se as iniciativas desenvolvidas pelo IFPR e pelo IFRS. De acordo como os PDI analisados, todos os IF têm a indicação de atendimento às leis vigentes e a busca pelo atendimento das demandas locais e regionais. 
Sobre a análise realizada no PDI do IFPR, ficam algumas indagações diante das informações levantadas: quais seriam as indicações de ações complementares que não estão previstas nas normas que orientam a abertura de novos cursos? O que poderia ser considerada uma metodologia coerente para tratar do assunto? Estas ações foram indicadas por alguns campi como necessárias.

Com isso, fica evidente, diante do cenário apresentado, a necessidade de novas produções e estudos que tratem da temática e que possam colaborar para que a oferta de novos cursos pela Rede Federal se dê em parceria com a sociedade e em beneficio da transformação social.

\section{REFERÊNCIAS}

BRASIL. Lei 11.892 de 29 de dezembro de 2008. Institui a Rede Federal de Educação Profissional, Científica e Tecnológica, cria os Institutos Federais de Educação, Ciência e Tecnologia e dá outras providências. Diário Oficial da União. Brasília, DF, 29 de Dez. 2008. Disponível em: < http://www.planalto.gov.br/ccivil_03/_ato2007-2010/2008/lei/111892.htm>. Acesso em: 05 jun. 2019.

BRASIL. Ministério da Educação. DIRETRIZES CURRICULARES NACIONAIS PARA A EDUCAÇÃO PROFISSIONẢL TÉCNICA DE NÍVEL MÉDIO EM DEBATE. 2012. Disponível em:

<http://portal.mec.gov.br/index.php?option=com_docman\&view=download\&alias=6695-dcnparaeducacao-profissional-debate\&Itemid=30192 > Acesso em: 25 mai. 2019.

BRASIL. Ministério da Educação. Expansão da Rede Federal. 2016. Disponível em: <http://redefederal.mec.gov.br/expansao-da-rede-federal>. Acesso em: 05 nov. 2018.

BRASIL. Decreto no 9.235, de 15 de dezembro de 2017. Decreto N$^{\circ}$ 9.235, de 15 de Dezembro de 2017: Dispõe sobre o exercício das funções de regulação, supervisão e avaliação das instituições de educação superior e dos cursos superiores de graduação e de pós-graduação no sistema federal de ensino. Brasília, 15 dez. 2017. Disponível em: <http://www.planalto.gov.br/ccivil_03/_Ato20152018/2017/Decreto/D9235.htm>. Acesso em: 10 jun. 2019.

BRASIL. Ministério da Educação. Catálogo Nacional de Cursos Técnicos. 2018. Disponível em: $<$ http://portal.mec.gov.br/secretaria-de-regulacao-e-supervisao-da-educacao-superior-seres/30000uncategorised/52031-catalogo-nacional-de-cursos-tecnicos> Acesso em: 20 de Mai. 2019.

INSTITUTO FEDERAL DO PARANÁ. Instrução Interna de Procedimentos PROENS/IFPR n 18. Curitiba: Instituto Federal do Paraná, 2011. 5 p. Disponível em: $<$ http://reitoria.ifpr.edu.br/wp-content/uploads/2014/11/n\%C2\%B0-018-dezembro-de2011.pdf > Acesso em: 11 mar. 2018. 
INSTITUTO FEDERAL DO PARANÁ. Plano de Desenvolvimento Institucional. Curitiba: Instituto Federal do Paraná, 2014. 764 p. Disponível em: <http://reitoria.ifpr.edu.br/wpcontent/uploads/2017/01/Anexo-Res.-13.2017.pdf>. Acesso em: 11 out. 2017.

INSTITUTO FEDERAL FARROUPILHA. Plano de Desenvolvimento Institucional. Rio Grande do sul: Instituto Federal Farroupilha, 2014. 395 p. Disponível em: $<$ https://www.iffarroupilha.edu.br/documentos-do-pdi/item/8369-plano-de-desenvolvimentoinstitucional-2014-2018>. Acesso em: 28 mai. 2019.

INSTITUTO FEDERAL DE EDUCAÇÃO, CIÊNCIA E TECNOLOGIA DO RIO GRANDE DO SUL. Plano de Desenvolvimento Institucional do Instituto Federal do RS 2014 - 2018. Bento Gonçalves: Instituto Federal do Rio Grande do Sul, 2014. 263 p. Disponível em: < https://ifrs.edu.br/documentos/plano-de-desenvolvimento-institucional-pdi-2014-2018/>. Acesso em: 28 mai. 2019.

INSTITUTO FEDERAL DE EDUCAÇÃO, CIÊNCIA E TECNOLOGIA SUL-RIOGRANDENSE. Plano de Desenvolvimento Institucional agosto de 2014 a dezembro de 2019. Rio grande do Sul: 2014. 136 p. Disponível em: < http://www.ifsul.edu.br/plano-de-desenvinstitucional>. Acesso em: 28 mai. 2019.

INSTITUTO FEDERAL CATARINENSE. Plano de Desenvolvimento Institucional do Instituto Federal Catarinense. Blumenau: 2014. 106 p. Disponível em: < http://concordia.ifc.edu.br/wpcontent/uploads/2016/10/PDI-2014_2018.pdf >. Acesso em: 28 mai. 2019.

INSTITUTO FEDERAL SANTA CATARINA. PLANO DE DESENVOLVIMENTO INSTITUCIONAL 2015-2019. Santa Catarina. 2015. 294 p. Disponível em: <https://pdi.ifsc.edu.br/download/faca-o-download-do-pdi-2015-2019/>. Acesso em: 28 mai. 2019

INSTITUTO FEDERAL DO PARANÁ. Instrução Interna de Procedimentos PROENS/IFPR n 01. Curitiba: Instituto Federal do Paraná, 2016. 12 p. Disponível em: <http://reitoria.ifpr.edu.br/wpcontent/uploads/2014/10/IIP-01-2016.pdf.pdf >Acesso em: 11 mar. 2018.

INSTITUTO FEDERAL DO PARANÁ. Instrução Interna de Procedimentos PROENS/IFPR n 02. Curitiba: Instituto Federal do Paraná, 2017. 26 p. Disponível em: $<$ http://reitoria.ifpr.edu.br/wpcontent/uploads/2014/10/IIP-PROENS-02-2017-OFERTA-DE-CURSOS-REGULARES-NOIFPR.pdf > Acesso em: 11 mar. 2018.

INSTITUTO FEDERAL DO PARANÁ. INSTRUÇÃO INTERNA DE PROCEDIMENTOS PROENS/ IFPR N 04, DE 27 DE SETEMBRO DE 2018. Curitiba: Instituto Federal do Paraná, 
2018. 33 p. Disponível em:<http://reitoria.ifpr.edu.br/wp-content/uploads/2018/10/IIP-42018.pdf> Acesso em: 11 jun. 2019.

INSTITUTO FEDERAL DO TOCANTINS. INSTRUÇÃO NORMATIVA N. 1/2018/REITORIA/IFTO, DE 26 DE MARÇO DE 2018. Palmas: Instituto Federal do Tocantins, 2018. 112 p. Disponível em:< http://www.ifto.edu.br/ifto/colegiados/consup/documentosaprovados/in-aprovada/2018/instrucao-normativa-1-2018.pdf/view>Acesso em: 10 jun. 2019.

TURMEN, Leandro; AZEVEDO, Mário Luiz Neves de. A expansão da Rede Federal de Educação Profissional, Científica e Tecnológica: os Institutos Federais em questão. Rev. Diálogo Educacional, Curitiba, v. 17, n. 54, p.1067-1084, 2017. Disponível em: <https://periodicos.pucpr.br/index.php/dialogoeducacional/article/view/21938>. Acesso em: 30 mai. 2019.

SEVERINO, Antônio Joaquim, 1941- Metodologia do trabalho científico. 23. ed. ver. e atual. São Paulo: Cortez, 2007. 